\title{
Electronic medical records: preparing for the inevitable crash
}

I t happened to a hospital in Boulder, Colorado, last March. It happened to seven hospitals in the East Bay area of California last August. In the early months of 2013, it happened to hundreds of family doctors in Nova Scotia. It has happened to health care providers in England, Australia and other parts of the world.

All of these facilities and physicians use electronic medical record (EMR) systems, and all were left scrambling to function when their system crashed. If multiple hospitals use the same system, the scale of the problem is even larger when an outage occurs.

"A computer system lets you do and control more things at once," says Dean Sittig, a professor in the School of Biomedical Informatics at the University of Texas Health Science Center at Houston. "But when it goes down, you can have bigger accidents.'

Sittig and two colleagues recently completed a study, as yet unpublished, of how often EMR systems fail. They found that not only are system crashes common, they are pretty much inevitable. The public is probably unaware of this, suggests Sittig, because news of a crash tends to escape a hospital's walls only when a ticked-off patient calls a reporter.

"We received survey responses from 50 institutions. Nearly all $(96 \%)$ institutions reported at least one unplanned downtime (of any length) in the last 3 years and $70 \%$ had at least one unplanned downtime greater than 8 hours in the last 3 years," states an email from study contributor Dr. Hardeep Singh, chief of the Health Policy, Quality and Informatics Program at the Center for Innovations in Quality, Effectiveness and Safety at the Michael E. DeBakey Veterans Affairs Medical Center in Houston, Texas.

A few years ago, the Memorial Hermann Health System in Houston, which Sittig is affiliated with, experienced its own crash. A dozen hospitals lost their EMR system for 10 hours. The problem was traced back to a single faulty computer server. "It had a five-year warranty, which had just expired," says Sittig. "Now we have two of those machines."

During a downtime, many activities become much more difficult. For exam-

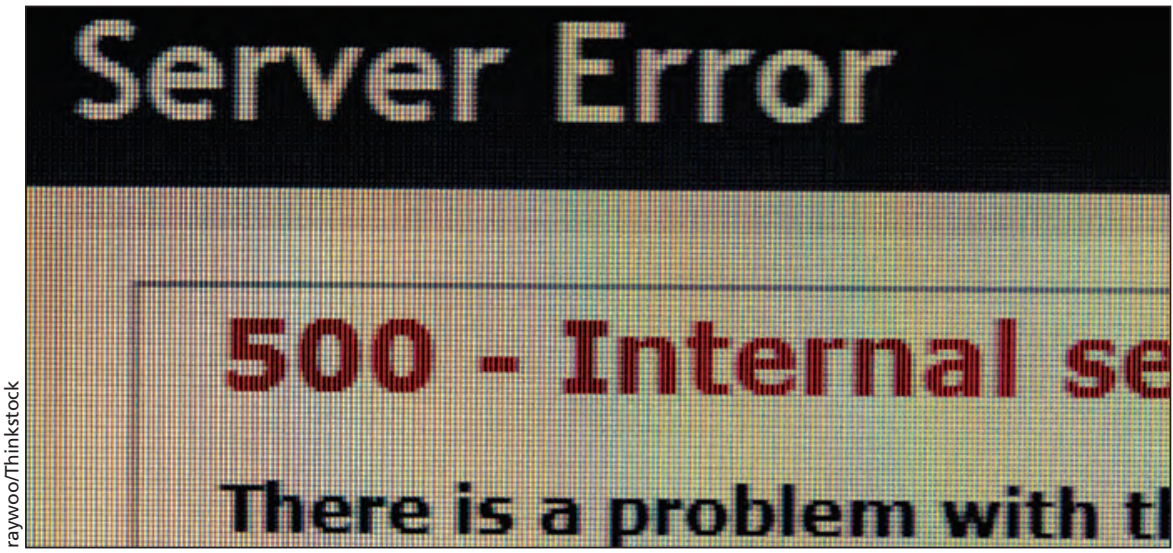

An EMR system could crash for many reasons, including server failure or human error.

ple, hospitals get backed up because patients can't be registered or discharged. Communication between departments becomes difficult, as does ordering medication and getting test results back from labs. Perhaps the most difficult task to perform well is billing for all services rendered. When using a backup paper system, a lot of the little things that usually enter the system with a touch of a button go unrecorded, says Sittig. If the EMR system outrage affects many hospitals, each with hundreds of patients, that can add up rather quickly.

"A lot of people have estimated that it can cost up to a million dollars an hour in lost charges," says Sittig.

\section{Prevent but be prepared}

There are a number of safeguards, however, that can help prevent system failures. And there are practices to mitigate the effects of a crash if those safeguards eventually prove inadequate. It all depends, though, on the type of system a hospital or practice is using, according to Dr. Alan Brookstone, founder of CanadianEMR, a website that reviews and ranks EMR systems.

Doctors who own their own systems and run them locally should have regular maintenance on all hardware and software. There should be redundancy in the hardware in the event of device failure. It is also important to not only regularly backup all data, but also to regularly test that the backups are working.

"Should your system go down, you are then able to go back and reinstall all the patient and system data so you can get back up and running," says Brookstone.

If, on the other hand, the EMR system is run by a third party in a remote location, the primary issue to address is potential connectivity problems. The vendor will be responsible for maintaining hardware and software. But the hospital or doctor's office will be responsible for ensuring their connection to the system remains uninterrupted. If you connect over the Internet, for example, it would be wise to have a second Internet provider install a line onsite.

'It doesn't have to be super highspeed, but it's available to you should your first line go down," says Brookstone.

According to Sittig, however, there is still plenty of room for improvement in creating robust and reliable EMR systems. Medicine has been rather late to the game in adopting sophisticated electronic systems compared to other sectors, such as the financial industry. It stands to reason that health care providers are also behind in adopting the best strategies to prevent downtimes.

By way of example, Sittig points to a large computing centre for a major oil and gas company in Houston. It handles transactions at gas stations all over the world, and it's a safe bet that their system has more sophisticated failsafes and backups than you would find in the medical world.

"Downtime is not an option for them," says Sittig. "We are talking about millions of dollars per second." - Roger Collier, CMAJ

CMAJ 2014. DOI:10.1503/cmaj.109-4719 